\title{
PENILAIAN KINERJA KEPALA SEKOLAH/MADRASAH SMA/SMK DI KECAMATAN BUMIAYU MENGGUNAKAN METODE TOPSIS
}

\author{
Tyas Pratama Puja Kususma ${ }^{1}$, Nurul Mega Saraswati ${ }^{2}$ \\ ${ }^{1}$ Program Studi Sistem Informasi \\ ${ }^{2}$ Program Studi Teknik Informatika \\ STMIK AMIKOM Purwokerto \\ Email: tyaspratamapujakusuma@gmail.com¹,nurul.mega.s@gmail.com²
}

\begin{abstract}
ABSTRAK
Penilaian kepala sekolah adalah salah satu penilaian kinerja pendidik dan tenaga pendidik untuk menjaga profesionalitas saat menjalankan tugas. Penilaian kinerja kepala sekolah dilakukan dengan memberikan penilaian berdasarkan data yang relevan. Penilaian dilakukan dengan tahapan wawancara, penilaian dan perhitungan nilai. Penelitian ini tentang sistem penunjang keputusan dengan menggunakan metode TOPSIS. Obyek penelitian ini adalah Kepala Sekolah/Madrasah SMA/SMK di Kecamatan Bumiayu. Penelitian ini mengasilkan preferensi pada alternatif A5 dengan nama Bapak Subagyo Sudrijat, M.Pd dengan preferensi kriteria kompetensi kepribadian sebagai pemimpin, kompetensi supervisi dan kompetensi kewirausahaan. Sedangkan kriteria kompetensi prestasi sebagai pendidik dan kompetensi sosial di preferensi A1 dengan bapak Drs. Budiyanto, M. Pd., dan kompetensi manajerial di preferensi pada bapak Drs. Joko Waseso, M. Pd.
\end{abstract}

Kata Kunci: Kinerja Kepala Sekolah, Sistem Penunjang Keputusan, TOPSIS, SMA, SMK

\begin{abstract}
Assessment of the principal is one of the assessment of the performance of educators and educators to maintain professionalism while performing their duties. Assessment of principals performance is done by providing an assessment based on relevant data. Assessment is done by interview stage, valuation and value calculation. This research is about decision support system by using TOPSI)method. The object of this research is the principal/Madrasah of SMA/SMK in District Bumiayu. This study yields preference on alternative A5 with the name of Mr. Subagyo Sudrijat, M.Pd with preference criteria of personality competence as a leader, supervision competence and entrepreneurial competence. While the criteria of achievement competence as educator and social competence in preference Al with the father Drs. Budiyanto, M. Pd., And managerial competence in preference to Mr. Drs. Joko Waseso, M. Pd.
\end{abstract}

Keywords: Principal Performance, Decision Support System, TOPSIS, SMA, SMK 


\section{PENDAHULUAN}

Berdasarkan Permendiknas No. 13 Tahun 2007 tentang Standar Kepala Sekolah/Madrasah dan Permendiknas No. 28 Tahun 2010 tentang Penugasan guru sebagai Kepala Sekolah/Madrasah, Pasal 12 menyatakan bahwa : (1) Penilaian kinerja kepala sekolah/madrasah dilakukan secara berkala setiap tahun dan secara kumulatif setiap empat tahun; (2) Penilaian kinerja tahunan dilakukan oleh pengawas sekolah/madrasah; (3) Penilaian kinerja empat tahunan dilaksanakan oleh atasan langsung dengan mempertimbangkan penilaian kinerja oleh tim penilaian dari pengawas sekolah/madrasah, pendidik, tenaga pendidik, dan komite sekolah/madrasah dari tempat bertugas; (4) Hasil penilaian kinerja dikategorikan dalam tingkatan amat baik, baik, cukup, sedang atau kurang.

Penilaian kepala sekolah adalah salah satu penilaian kinerja pendidik dan tenaga pendidik untuk menjaga profesionalitas saat menjalankan tugas, menciptakan suasana pendidikan yang bermakna, meningkatkan mutu pendidikan dan meningkatakan kopetensi sekolah/madrasah. Kinerja kepala sekolah bisa berkontribusi dalam meningkatkan kemampuan secara terstruktur dengan proses perbaikan mutu agar menjaga kualitasnya.

Penilaian kinerja kepala sekolah/madrasah dilakukan dengan memberikan penilaian setiap penilaian berdasarkan data yang relevan. Penilaian yang dilakukan dengan tahapan wawancara, penilaian dan perhitungan nilai. (Khotimah, 2016) Penilaian kinerja kepala sekolah/madrasah berupa enam kriteria, yaitu: kompetensi sebagai pendidik, kompetensi manajerial, kompetensi supervisi, kompetensi kepribadian (sebagai pemimpin), kompetensi kewirausahaan, dan kompetensi sosial. Di mana tiap kriteria memiliki sub-kriteria dengan skala 1 sampai 4 yang menyatakan pertnyataan amat baik, baik, cukup dan kurang.

Penelitian mengusulkan tentang sistem penunjang keputusan dengan menggunakan metode Technique for Order of Preference by Similarity to Ideal Solution (TOPSIS) dalam penilian kinerja kepala sekolah/madrasah SMA/SMK di kecamatan Bumiayu. Penilitian ini tidak hanya untuk penilaian kinerja kepala 
sekolah/madrasah SMA/SMK, tetapi bisa digunakan dalam berkompetisi yang berkualitas di dunia pendidikan terutama di kecamatan Bumiayu.

\section{METODE PENELITIAN}

Penelitian dilakukan meggunakan metode TOPSIS (Technique for Order of Preference by Similarity to Ideal Solutio) untuk menghitung beberapa pemilihan penilian kriteria dan standar penilian di setiap kriteria. Metode TOPSIS pertama kali diperkenalkan oleh Yoon dan Hwang pada tahun 1981 dengan berkonsep menggunkan kriteria yang bersifat benefit dan cost, karakteristik pada alternatif terpilih berdasarkan pemilihan terbaik yang memiliki jarak terpendek dari soulusi ideal positif dan jarak terpanjang dari solusi ideal negative (Sri Kusumadewi 2006). Alasan menggunakan metode ini karena memiliki kemampuan dalam mengukur kinerja relatif dari alternetif-alternatif keputusan yang lebih sederhana. Langkahlangkah dalam menyelesaikan permasalaha menggunakan metode TOPSIS adalah sebagai berikut:

1. Membuat matrik keputusan yang ternormalisasi

Mendapatkan nilai matrik normalisasi (r), di mana setiap alternatif $\mathrm{A}_{i}$ pada setiap kriteria $\mathrm{C}_{j}$ yang ternormalisasi, yaitu :

$r_{i j}=\frac{X_{i j}}{\sqrt{\sum_{i=1}^{m} X_{i j}^{2}}}$

Dengan $\mathrm{i}=1,2, \ldots \ldots, \mathrm{m} ;$ dan $\mathrm{j}=1,2,3, \ldots ., \mathrm{n}$

Keterangan:

$\mathrm{r}_{i j} \quad$ : nilai rating kinerja ternomalisasi

$\mathrm{X}_{i j}$ : nilai atribut yang dimiliki dari setiap kriteria

2. Membuat matrik keputusan yang ternormalisasi terbobot

Hasil dari matrik normalisasi kemudian dikalikan dengan bobot preferensi (w) yang sudah ditentukan dengan rumus:

y_ij=w_i r_ij

Dengan $\mathrm{i}=1,2, \ldots \ldots, \mathrm{m} ;$ dan $\mathrm{j}=1,2,3, \ldots \ldots, \mathrm{n}$

Keterangan: 
$\mathrm{y}_{i j}$ : normalisasi terbobot

$\mathrm{w}_{i}$ : nilai bobot dari kreteria

$\mathrm{r}_{i j}$ : nilai rating kinerja ternomalisasi

3. Mentukan matrik solusi ideal positif dan matrik solusi ideal negatif

Nilai $\mathrm{V}_{i}$ yang lebih besar menunjukkan bahwa alternatif $\mathrm{A}_{i}$ lebih terpilih.

Rumusnya, yaitu:

$$
\begin{aligned}
& A^{+}=\left(y_{1}^{+}, y_{2}^{+}, \ldots, y_{n}^{+}\right) \\
& A^{-}=\left(y_{1}^{-}, y_{2}^{-}, \ldots, y_{n}^{-}\right)
\end{aligned}
$$

Di mana:

$$
\begin{aligned}
& y_{j}^{+}=\left\{\begin{array}{l}
{\underset{i}{\max } y_{i j} ; \text { jika } \mathrm{j} \text { adalah atribut keuntungan }} \\
\min _{i}^{\min } y_{i j} ; \mathrm{jika} \mathrm{j} \text { adalah atribut biaya }
\end{array}\right. \\
& y_{j}^{-}=\left\{\begin{array}{l}
{ }_{i}^{\min } y_{i j} ; \text { jika } \mathrm{j} \text { adalah atribut keuntungan } \\
\max _{i}^{\max } y_{i j} ; \text { jika } \mathrm{j} \text { adalah atribut biaya }
\end{array}\right.
\end{aligned}
$$

Dengan $\mathrm{i}=1,2, \ldots \ldots, \mathrm{m} ;$ dan $\mathrm{j}=1,2,3, \ldots \ldots, \mathrm{n}$

Keterangan:

A+ : solusi ideal positif

A- : solusi ideal negatif

4. Menentukan jarak antara nilai setiap alternatif dengan matrik solusi ideal positif dan matrik solusi ideal negatif

Jarak antara alternatif $\mathrm{A}_{i}$ dengan solusi ideal positif dirumuskan;

$$
D_{i}^{+}=\sqrt{\sum_{j=1}^{n}\left(y_{j}^{+}-y_{i j}\right)^{2}}
$$

Jarak antara alternatif $\mathrm{A}_{i}$ dengan solusi ideal positif dirumuskan;

$$
D_{i}^{-}=\sqrt{\sum_{j=1}^{n}\left(y_{j}^{-}-y_{i j}\right)^{2}}
$$

Dengan $\mathrm{i}=1,2, \ldots . ., \mathrm{m} ;$ dan $\mathrm{j}=1,2,3, \ldots \ldots, \mathrm{n}$

5. Menentukan nilai preferensi untuk setiap alternatif $\left(\mathrm{V}_{i}\right)$, sebagai berikut : 


$$
V_{i}=\frac{D_{i}^{+}}{D_{i}^{-}+D_{i}^{+}} ; \mathrm{j}=1,2,3, \ldots \ldots, \mathrm{m}
$$

Nilai $\mathrm{V}_{i}$ yang lebih besar menunjukan alternatif $\mathrm{A}_{i}$ yang lebih dipilih.

\section{HASIL DAN PEMBAHASAN}

\section{Kriteria dan Bobot}

Pada penelitian yang dilakukan terdapat beberapa kriteria dan bobot untuk menilai kinerja kepala sekolah yang paling berprestasi. Kriteria yang digunakan untuk penilian kinerja kepala sekolah terdiri dari kriteria utama dan sub-kriteria. Menggunakan skala 1 sampai 4 dengan nilai amat baik, baik, cukup, sedang atau kurang. Adapun kriteria utama pada tabel 1, sebagai berikut:

Tabel 1 Kriteria Utama Kinerja Kepala Sekolah

\begin{tabular}{|c|c|l|}
\hline No. & Kreteria & \multicolumn{1}{|c|}{ Keterangan } \\
\hline 1 & C1 & Kompetensi sebagai Pendidik \\
\hline 2 & C2 & Kompetensi Manajerial \\
\hline 3 & C3 & Kompetensi Supervisi \\
\hline 4 & C4 & Kompetensi Kepribadian (sebagai Pemimpin) \\
\hline 5 & C5 & Kompetensi Kewirausahaan \\
\hline 6 & C6 & Kompetensi Sosial \\
\hline
\end{tabular}

Penilian pembobotan untuk setiap kriteria memiliki total 500, tiap kriteria memiliki sub kriteria. Berikut tabel 2 adalah bobot tiap sub-kreteria:

Tabel 2 Bobot Sub-Kreteria

\begin{tabular}{|c|c|c|c|}
\hline No. & Kriteria & Sub-Kreteria & Bobot \\
\hline \multirow{2}{*}{ C1 } & $\begin{array}{l}\text { 1. Kompetensi } \\
\text { Sebagai } \\
\text { Pendidik }\end{array}$ & 1.1. Prestasi sebagai pendidik & 30 \\
\hline
\end{tabular}




\begin{tabular}{|c|c|c|c|}
\hline \multirow{10}{*}{$\mathrm{C} 2$} & \multirow{10}{*}{$\begin{array}{l}\text { 2. Kompetensi } \\
\text { Manajerial }\end{array}$} & 2.1. Kemampuan menyusun program sekolah & 15 \\
\hline & & $\begin{array}{l}\text { 2.2. Kemampuan menyusun struktur organisasi } \\
\text { sekolah }\end{array}$ & 20 \\
\hline & & $\begin{array}{l}\text { 2.3. Kemampuan menggerakan tenaga pendidik } \\
\text { dan kependidikan (pendidikan dan tenaga } \\
\text { pendidik) }\end{array}$ & 15 \\
\hline & & $\begin{array}{l}\text { 2.4. Kemampuan mengoptimalkan sumberdaya } \\
\text { sekola }\end{array}$ & 25 \\
\hline & & $\begin{array}{l}\text { 2.5. Kemapuan mengelola administrasi PBM dan } \\
\text { BK }\end{array}$ & 20 \\
\hline & & $\begin{array}{l}\text { 2.6. Kemampuan mengelola administrasi } \\
\text { kesiswaan }\end{array}$ & 15 \\
\hline & & $\begin{array}{l}\text { 2.7. Kemampuan mengelola administrasi } \\
\text { pendidik dan tenaga kependidikan }\end{array}$ & 10 \\
\hline & & $\begin{array}{l}\text { 2.8. Kemampuan mengelola administrasi } \\
\text { keuangan }\end{array}$ & 15 \\
\hline & & $\begin{array}{l}\text { 2.9. Kemampuan mengelola administrasi } \\
\text { sarana/prasaran }\end{array}$ & 25 \\
\hline & & $\begin{array}{r}\text { 2.10. Kemampuan mengelola } \\
\text { administrasiZpersuratan }\end{array}$ & 10 \\
\hline \multirow{3}{*}{$\mathrm{C} 3$} & \multirow{3}{*}{$\begin{array}{l}\text { 3. Kompetensi } \\
\text { Supervisi }\end{array}$} & $\begin{array}{l}\text { 3.1. Kemampuan menyusun program supervisi } \\
\text { pendidikan }\end{array}$ & 15 \\
\hline & & $\begin{array}{l}\text { 3.2. Kemampuan melaksanakan program } \\
\text { supervisi pendidikan }\end{array}$ & 15 \\
\hline & & 3.3. Kemampuan memanfaatkan hasil supervisi & 10 \\
\hline \multirow[b]{2}{*}{$\mathrm{C} 4$} & \multirow{2}{*}{$\begin{array}{l}\text { 4. Kompetensi } \\
\text { Kepribadian }\end{array}$} & 4.1. Memiliki kepribadian yang kuat & 30 \\
\hline & & $\begin{array}{r}\text { 4.2. Memahami kondisi pendidik, tenaga } \\
\text { kependidikan dan siswa dengan baik }\end{array}$ & 30 \\
\hline
\end{tabular}




\begin{tabular}{|c|c|c|c|}
\hline & (Sebagai & 4.3. Memiliki dan memahami visi, misi sekolah & 15 \\
\hline & Pemimpin) & 4.4. Kemampuan mengambil keputusan & 15 \\
\hline & & 4.5. Kemampuan berkomunikasi & 20 \\
\hline & & $\begin{array}{l}\text { 5.1. kemampuan mencari/menemukan gagasan } \\
\text { baru untuk pembaharun sekolah }\end{array}$ & 15 \\
\hline$C_{5}$ & $\begin{array}{l}\text { 5. Kompetensi } \\
\text { Kewirausahaan }\end{array}$ & $\begin{array}{l}\text { 5.2. kemampuan melaksanakan pembahuruan di } \\
\text { sekolah }\end{array}$ & 30 \\
\hline J & & $\begin{array}{l}\text { 5.3. kemampuan mengembangkan } \\
\text { sarana/prasarana }\end{array}$ & 10 \\
\hline & & $\begin{array}{l}\text { 5.4. kemampuan mengubah peluang menjadi } \\
\text { program/kegiatan yang menguntungkan }\end{array}$ & 15 \\
\hline & & $\begin{array}{l}\text { 1.1. kemampuan mengatur lingkungan kerja } \\
\text { (fisik) }\end{array}$ & 25 \\
\hline C6 & Sosial & $\begin{array}{l}\text { 1.2. kemampuan mengatur suasana kerja (non- } \\
\text { fisik) }\end{array}$ & 20 \\
\hline & & $\begin{array}{l}\text { 1.3. kemampuan menerapkan prinsip } \\
\text { penghargaan dan hukuman }\end{array}$ & 15 \\
\hline & & TOTAL & 500 \\
\hline
\end{tabular}

Adapun kandidat yang akan menjadi alternatif pada kasus kinerja kepala sekolah, yang terlihat pada tabel 3 .

Tabel 3 Jenis Alternatif

\begin{tabular}{|c|c|l|}
\hline No. & Alternatif & \multicolumn{1}{|c|}{ Keterangan } \\
\hline 1 & A1 & Drs. Budiyanto, M. Pd. \\
\hline 2 & A2 & Drs. Joko Waseso, M. Pd. \\
\hline 3 & A3 & Mungal, M. Pd \\
\hline 4 & A4 & Subagyo Sudrijat, S. Pd, M.MPd \\
\hline 5 & A5 & Drs. Darsono, M.MPd \\
\hline
\end{tabular}




\section{Perhitungan TOPSIS}

a. Kompetensi sebagai Pendidik

- Tabel nilai sub-kriteria di Kompetensi sebagai Pendidik

Nilai tiap alternatif pada sub-kriteria kompetensi sebagai pendidik terlihat pada tabel 4, sebagai berikut:

Tabel 4 Nilai Preferensi Kompetensi Sebaai Pendidik

\begin{tabular}{|l|l|l|l|l|l|l|}
\hline & C1 & C2 & C3 & C4 & C5 & C6 \\
\hline A1 & 4 & 2 & 1 & 3 & 1 & 3 \\
\hline A2 & 3 & 2 & 2 & 4 & 2 & 2 \\
\hline A3 & 2 & 3 & 2 & 3 & 1 & 1 \\
\hline A4 & 2 & 2 & 4 & 4 & 1 & 3 \\
\hline A5 & 4 & 4 & 3 & 4 & 4 & 2 \\
\hline & 7 & 6,08 & 5,83 & 8,12 & 4,8 & 5,2 \\
\hline
\end{tabular}

- Tabel normalisasi (R) perkolom sub-kriteria di Kompetensi sebagai Pendidik

Pada tahap ini, kita hitung matrik normalisasikan (R) dengan rumus 2.1 yang terlihat pada tabel 5, sebagai berikut:

Tabel 5 Normalisasi Perkolom Kompetensi Sebagai Pendidik

\begin{tabular}{|l|l|l|l|l|l|l|}
\hline & C1 & C2 & C3 & C4 & C5 & C6 \\
\hline A1 & 0,57 & 0,33 & 0,17 & 0,37 & 0,21 & 0,58 \\
\hline A2 & 0,43 & 0,33 & 0,34 & 0,49 & 0,42 & 0,38 \\
\hline A3 & 0,29 & 0,49 & 0,34 & 0,37 & 0,21 & 0,19 \\
\hline A4 & 0,29 & 0,33 & 0,69 & 0,49 & 0,21 & 0,58 \\
\hline A5 & 0,57 & 0,66 & 0,51 & 0,49 & 0,83 & 0,38 \\
\hline
\end{tabular}


- Matrik ternormalisasi terbobot (Y) sub-kriteria di Kompetensi sebagai Pendidik

Setelah mendapatkan nilai $\mathrm{R}$ kemudian, menghitung dengan rumus 2.3 dimana $w=5,5,5,5,5,5$. Dapat dilihat pada tabel 6 .

Tabel 6 Matrik Ternomalisasi Terbobot Kompetensi Sebagai Pendidik

\begin{tabular}{|l|l|l|l|l|l|l|}
\hline & C1 & C2 & C3 & C4 & C5 & C6 \\
\hline A1 & 2,86 & 1,64 & 0,86 & 1,85 & 1,04 & 2,89 \\
\hline A2 & 2,14 & 1,64 & 1,71 & 2,46 & 2,09 & 1,92 \\
\hline A3 & 1,43 & 2,47 & 1,71 & 1,85 & 1,04 & 0,96 \\
\hline A4 & 1,43 & 1,64 & 3,43 & 2,46 & 1,04 & 2,89 \\
\hline A5 & 2,86 & 3,29 & 2,57 & 2,46 & 4,17 & 1,92 \\
\hline
\end{tabular}

- Menentukan matrik solusi ideal positif dan matrik solusi ideal negatif sub-kriteria di Kompetensi sebagai Pendidik

Pada kasus ini menentukan benefit atau cost, sehingga menggunakan rumus 2.3 dan 2.4, untuk menentukan solusi ideal positif dan solusi ideal negatif. Nilai A+ dari nilai Y paling tinggi dan A- dari nilai minimal Y karena termasuk benefit, bisa dilihat pada tabel 7.

Tabel 7 Menentukan Solusi Ideal Kompetensi Sebagai Pendidik

\begin{tabular}{|l|r|r|r|r|r|r|}
\hline A+ & 2,86 & 3,29 & 3,43 & 2,46 & 4,17 & 2,89 \\
\hline A- & 1,43 & 1,64 & 0,86 & 1,85 & 1,04 & 0,96 \\
\hline
\end{tabular}

- Mentukan jarak dengan matrik solusi ideal positif dan solusi ideal negatif sub-kriteria di Kompetensi sebagai Pendidik

Tabel 8 Jarak Solusi Ideal Positif Kompetensi Sebagai Pendidik

\begin{tabular}{|c|c|c|c|c|c|c|c|c|c|c|}
\hline A+ & Y1 & Y2 & Y3 & Y4 & Y5 & D1 & D2 & D3 & D4 & D5 \\
\hline 2,86 & 2,86 & 2,14 & 1,43 & 1,43 & 2,86 & 0 & 0,52 & 2,04 & 2,04 & 0 \\
\hline 3,29 & 1,64 & 1,64 & 2,47 & 1,64 & 3,29 & 2,72 & 2,72 & 0,67 & 2,72 & 0 \\
\hline
\end{tabular}




\begin{tabular}{|c|c|c|c|c|c|c|c|c|c|c|}
3,43 & 0,86 & 1,71 & 1,71 & 3,43 & 2,57 & 6,60 & 2,96 & 2,96 & 0 & 0,74 \\
\hline 2,46 & 1,85 & 2,46 & 1,85 & 2,46 & 2,46 & 0,37 & 0 & 0,37 & 0 & 0 \\
\hline 4,17 & 1,04 & 2,09 & 1,04 & 1,04 & 4,17 & 9,80 & 4,33 & 9,80 & 9,80 & 0 \\
\hline 2,89 & 2,89 & 1,92 & 0,96 & 2,89 & 1,92 & 0 & 0,94 & 3,72 & 0 & 0,94 \\
\hline \multicolumn{3}{|c|}{ D+ } & & $\mathbf{4 , 4 2}$ & $\mathbf{3 , 3 9}$ & $\mathbf{4 , 4 2}$ & $\mathbf{3 , 8 2}$ & $\mathbf{1 , 3 0}$ \\
\hline
\end{tabular}

Tabel 9 Jarak Solusi Ideal Negatif Kompetensi Sebagai Pendidik

\begin{tabular}{|c|c|c|c|c|c|c|c|c|c|c|}
\hline A- & Y1 & Y2 & Y3 & Y4 & Y5 & D1 & D2 & D3 & D4 & D5 \\
\hline 1,43 & 2,86 & 2,14 & 1,43 & 1,43 & 2,86 & 2,04 & 0,50 & 0 & 0 & 2,04 \\
\hline 1,64 & 1,64 & 1,64 & 2,47 & 1,64 & 3,29 & 0 & 0 & 0,69 & 0 & 2,72 \\
\hline 0,86 & 0,86 & 1,71 & 1,71 & 3,43 & 2,57 & 0 & 0,72 & 0,72 & 6,60 & 2,92 \\
\hline 1,85 & 1,85 & 2,46 & 1,85 & 2,46 & 2,46 & 0 & 0,37 & 0 & 0,37 & 0,37 \\
\hline 1,04 & 1,04 & 2,09 & 1,04 & 1,04 & 4,17 & 0 & 1,10 & 0 & 0 & 9,80 \\
\hline 0,96 & 2,89 & 1,92 & 0,96 & 2,89 & 1,92 & 3,72 & 0,92 & 0 & 3,72 & 0,92 \\
\hline \multicolumn{6}{|c|}{ D - } & 2,40 & 1,90 & 1,19 & 3,27 & 4,33 \\
\hline
\end{tabular}

- Menentukan Preferensi sub-kriteria di Kompetensi sebagai Pendidik

Tabel 10 Preferensi Kompetensi Sebagai Pendidik

\begin{tabular}{|l|c|c|c|c|c|}
\hline V+ & 0,65 & 0,64 & 0,79 & 0,54 & 0,23 \\
\hline Preferences & $\mathbf{4}$ & $\mathbf{3}$ & $\mathbf{5}$ & $\mathbf{2}$ & $\mathbf{1}$ \\
\hline V- & 0,35 & 0,36 & 0,21 & 0,46 & 0,77 \\
\hline Preferences & $\mathbf{4}$ & $\mathbf{3}$ & $\mathbf{5}$ & $\mathbf{2}$ & $\mathbf{1}$ \\
\hline
\end{tabular}

Jadi, untuk prefensi sub-kriteria kompetensi sebagai pendidik adalah alternatif A5.

\section{b. Kompetensi Manajerial}

Nilai tiap alternatif pada sub-kriteria kompetensi manajerial terlihat pada tabel 11, sebagai berikut:

Tabel 11 Nilai Preferensi Kompetensi Manajerial

\begin{tabular}{|l|r|r|r|r|r|r|r|r|r|r|}
\hline & C1 & C2 & C3 & C4 & C5 & C6 & C7 & C8 & C9 & C10 \\
\hline A1 & 4 & 4 & 1 & 4 & 3 & 1 & 4 & 3 & 1 & 3 \\
\hline
\end{tabular}




\begin{tabular}{|l|r|r|r|r|r|r|r|r|r|r|}
\hline A2 & 3 & 3 & 2 & 2 & 1 & 2 & 2 & 4 & 2 & 2 \\
\hline A3 & 2 & 4 & 4 & 1 & 1 & 3 & 3 & 4 & 2 & 2 \\
\hline A4 & 2 & 2 & 1 & 3 & 2 & 4 & 1 & 3 & 3 & 3 \\
\hline A5 & 4 & 4 & 2 & 1 & 3 & 2 & 1 & 2 & 1 & 4 \\
\hline & 7 & 7,81 & 5,10 & 5,57 & 4,90 & 5,83 & 5,57 & 7,35 & 4,36 & 6,48 \\
\hline
\end{tabular}

Tahap selanjutnya seperti tahap pada sub-kriteria diatas, tetapi dengan bobot kriteria pada kompetensi manajerial adalah 15, 20, 15, 25, 20, 15, 10 , 15, 25, 10. Sehingga hasil preferensi kompetensi manajerial pada tabel 12 berada di alternatif A1.

Tabel 12 Hasil Preferensi Kompetensi Manajerial

\begin{tabular}{|l|r|r|r|r|r|}
\hline V+ & 0,42 & 0,65 & 0,56 & 0,51 & 0,99 \\
\hline Preferences & 1 & 4 & 3 & 2 & 5 \\
\hline V- & 0,58 & 0,35 & 0,44 & 0,49 & 0,01 \\
\hline Preferences & 1 & 4 & 3 & 2 & 5 \\
\hline
\end{tabular}

\section{c. Kompetensi Supervisi}

Nilai tiap alternatif pada sub-kriteria kompetensi supervisi terlihat pada tabel 13, sebagai berikut:

\section{Tabel 13 Nilai Preferensi Kompetensi Supervisi}

\begin{tabular}{|r|r|r|r|}
\hline & \multicolumn{1}{|l|}{ C1 } & \multicolumn{1}{l|}{ C2 } & \multicolumn{1}{l|}{ C3 } \\
\hline A1 & 4 & 2 & 1 \\
\hline A2 & 3 & 2 & 2 \\
\hline A3 & 2 & 3 & 2 \\
\hline A4 & 2 & 2 & 4 \\
\hline A5 & 4 & 4 & 3 \\
\hline & 7 & 6,08 & 5,83 \\
\hline
\end{tabular}


Tahap selanjutnya seperti tahap pada sub-kriteria diatas, tetapi dengan bobot kriteria pada kompetensi supervisi adalah 15, 15, 10. Sehingga hasil preferensi kompetensi supervisi pada tabel 14 berada di alternatif A5.

Tabel 14 Hasil Preferensi Kompetensi Supervisi

\begin{tabular}{|l|r|r|r|r|r|}
\hline V+ & 0,62 & 0,70 & 0,67 & 0,56 & 0,19 \\
\hline Preferences & 3 & 5 & 4 & 2 & 1 \\
\hline V- & 0,38 & 0,30 & 0,33 & 0,44 & 0,81 \\
\hline Preferences & 3 & 5 & 4 & 2 & 1 \\
\hline
\end{tabular}

\section{d. Kompetensi Kepribadian Sebagai Pemimpin}

Nilai tiap alternatif pada sub-kriteria kompetensi kepribadian sebagai pemimpin terlihat pada tabel 15 , sebagai berikut:

Tabel 15 Nilai Preferensi Kompetensi Kepribadian Sebagai Pemimpin

\begin{tabular}{|l|r|r|r|r|r|}
\hline & \multicolumn{1}{|l|}{ C1 } & C2 & C3 & C4 & \multicolumn{1}{l|}{ C5 } \\
\hline A1 & 1 & 1 & 4 & 1 & 3 \\
\hline A2 & 3 & 4 & 3 & 2 & 2 \\
\hline A3 & 2 & 3 & 1 & 4 & 2 \\
\hline A4 & 4 & 1 & 3 & 1 & 4 \\
\hline A5 & 2 & 2 & 3 & 4 & 4 \\
\hline & 5,83 & 5,57 & 6,63 & 6,16 & 7,00 \\
\hline
\end{tabular}

Tahap selanjutnya seperti tahap pada sub-kriteria diatas, tetapi dengan bobot kriteria pada kompetensi kepribadian sebagai pemimpin adalah 30, $30,15,15,20$. Sehingga hasil preferensi kompetensi manajerial pada tabel 16 berada di alternatif $\mathrm{A} 2$.

Tabel 16 Hasil Preferensi Kompetensi Manajerial

\begin{tabular}{|l|r|r|r|r|r|}
\hline $\mathrm{V}+$ & 0,42 & 0,65 & 0,56 & 0,51 & 0,99 \\
\hline Preferences & 0,76 & 0,32 & 0,511 & 0,509 & 0,54 \\
\hline
\end{tabular}




\begin{tabular}{|l|r|r|r|r|r|} 
V- & 5 & 1 & 3 & 2 & 4 \\
\hline Preferences & 0,24 & 0,68 & 0,489 & 0,491 & 0,46 \\
\hline
\end{tabular}

\section{e. Kompetensi Kewirausahaan}

Nilai tiap alternatif pada sub-kriteria kompetensi kewirausahaan terlihat pada tabel 17, sebagai berikut:

\section{Tabel 17 Nilai Preferensi Kompetensi Kewirausahaan}

\begin{tabular}{|r|r|r|r|r|}
\hline & C1 & C2 & C3 & \multicolumn{1}{l|}{ C4 } \\
\hline A1 & 2 & 1 & 3 & 4 \\
\hline A2 & 2 & 2 & 4 & 1 \\
\hline A3 & 3 & 2 & 2 & 2 \\
\hline A4 & 1 & 3 & 4 & 2 \\
\hline A5 & 4 & 2 & 1 & 4 \\
\hline & 5,83 & 4,69 & 6,78 & 6,40 \\
\hline
\end{tabular}

Tahap selanjutnya seperti tahap pada sub-kriteria diatas, tetapi dengan bobot kriteria pada kompetensi kewirausahaan adalah 15, 30, 10, 15 . Sehingga hasil preferensi kompetensi kewirausahaan pada tabel 18 berada di alternatif A5.

Tabel 18 Hasil Preferensi Kompetensi Kewirausahaan

\begin{tabular}{|l|r|r|r|r|r|}
\hline V+ & 0,64 & 0,57 & 0,51 & 0,397 & 0,390 \\
\hline Preferences & 5 & 4 & 3 & 2 & 1 \\
\hline V- & 0,36 & 0,43 & 0,49 & 0,603 & 0,610 \\
\hline Preferences & 5 & 4 & 3 & 2 & 1 \\
\hline
\end{tabular}

\section{f. Kompetensi Sosial}

Nilai tiap alternatif pada sub-kriteria kompetensi sosial terlihat pada tabel 19, sebagai berikut: 
Tabel 19 Nilai Preferensi Kompetensi Sosial

\begin{tabular}{|l|r|r|r|}
\hline & \multicolumn{1}{l|}{ C1 } & \multicolumn{1}{l|}{ C2 } & \multicolumn{1}{l|}{} \\
\hline A1 & 1 & 4 & 1 \\
\hline A2 & 3 & 2 & 3 \\
\hline A3 & 2 & 3 & 2 \\
\hline A4 & 2 & 1 & 3 \\
\hline A5 & 4 & 2 & 1 \\
\hline & $\mathbf{5 , 8 3}$ & $\mathbf{5 , 8 3}$ & $\mathbf{4 , 9 0}$ \\
\hline
\end{tabular}

Tahap selanjutnya seperti tahap pada sub-kriteria diatas, tetapi dengan bobot kriteria pada kompetensi sosial adalah 25, 20, 15. Sehingga hasil preferensi kompetensi sosial pada tabel 20 berada di alternatif A1.

Tabel 20 Hasil Preferensi Kompetensi Sosial

\begin{tabular}{|l|r|r|r|r|r|}
\hline V+ & 0,58 & 0,42 & 0,53 & 0,64 & 0,41 \\
\hline Preferences & $\mathbf{1}$ & $\mathbf{5}$ & $\mathbf{4}$ & $\mathbf{2}$ & $\mathbf{3}$ \\
\hline V- & 0,42 & 0,58 & 0,47 & 0,36 & 0,59 \\
\hline Preferences & $\mathbf{1}$ & $\mathbf{5}$ & $\mathbf{4}$ & $\mathbf{2}$ & $\mathbf{3}$ \\
\hline
\end{tabular}

\section{KESIMPULAN DAN SARAN}

Adanya penilian kinerja kepala sekolah menjadi penilian yang lebih subjektif dan lebih transparan. Penilian kinerja kepala sekolah SMA/Mandrasah SMA/SMK menggunakan perhitungan Sitem Pendukung Keputusan (SPK) dengan metode TOPSIS dan berhasil dilakukan. Mengasilkan preferensi pada alternatif A5 dengan nama Bapak Subagyo Sudrijat, M.Pd dengan preferensi kriteria kompetensi kepribadian sebagai pemimpin, kompetensi supervisi dan kompetensi kewirausahaan. Sedangkan kriteria kompetensi prestasi sebagai pendidik dan kompetensi sosial di preferensi A1 dengan bapak Drs. Budiyanto, M. Pd., dan kompetensi manajerial di preferensi pada bapak Drs. Joko Waseso, M. Pd. 


\section{DAFTAR PUSTAKA}

Daihani, D, U. 2001. Komputerisasi Pengambilan Keputusan. Bogor: Ghalia Indonesia.

Khotimah, Husnul. 2016. "Instrumen Penilaian Kinerja Kepala Sekolah Dasar 1. Dimensi Kompetensi Sebagai Pendidik (Pedagogik) Jumlah Nilai Indikator (Jni) 1 Aspek 30 2. Dimensi Kompetensi Manajerial." Retrieved (http://www.academia.edu/9850932/Instrumen_Penilaian_Kinerja_Kepala_ Sekolah_Dasar_1._Dimensi_Kompetensi_Sebagai_Pendidik_Pedagogik_Ju mlah_Nilai_Indikator_Jni_1_Aspek_30_2._Dimensi_Kompetensi_Manajeri al).

Kosasi, S. 2002. Sistem Penunjang Keputusan (Decision Support System). Pontianak.

Kusrini, 2007. Konsep dan Aplikasi Sistem Pendukung Keputusan, Andi Offset, Yogyakarta

Rasyid, Abdul dan Maharani, Septya. 2016. "Implementasi Technique For Order Preferences By Similary To Ideal Solution (TOPSIS) Pada Seleksi Asisten Laboratorium (Studi kasus : Laboratorium RPL FMIPA Universitas Mulawarman)". urnal Informatika Mulawarman, 48, 1858-4853.

Republik Indonesia. 2007. "Peraturan Menteri Pendidikan Nasional Nomor. 13 Tahun. 2007 Tentang Standar Kepala Sekolah/Madrasah.”

Republik Indonesia. 2010. Peraturan Menteri Pendidikan Nasional Nomor. 28 Tahun. 2010 Tentang Penugasan Guru Sebagai Kepala Sekolah/Madrasah.

Sri Kusumadewi. 2006. Fuzzy Mukti-Attribute Decision Making. Yogyakarta: Graha Ilmu.

Suryadi, K. dan Ramadhani, M. A.1998. Sistem Pendukung Keputusan: Suatu Wacana Struktural Idealisasi dan Implementasi Pengambilan Keputusan. Bandung: Remaja Rosdakarya Offset.

Turban, Efraim, Aronson, and Jay E. 2005. Decision Support System and Intellegent Systems. 7th Edition. New Jersey: Pearson Prentice - Hall Education Internasional. 